\title{
CARTA MAIOR E VEJA: SILENCIAMENTO NO CASO CHARLIE HEBDO
}

\author{
CARTA CAPITAL AND VEJA: WHISPER IN CASE CHARLIE HEBDO \\ Marilia Manfredi Gasparovic \\ Mestranda em Estudos Linguísticos pela Universidade Federal do Paraná \\ Graduada em Letras Português/Inglês e em Comunicação Social/Jornalismo \\ E-mail: marilia_mmg@hotmail.com
}

\section{RESUMO}

Este trabalho objetiva, à luz da Análise do Discurso de linha francesa, identificar as formações discursivas mobilizadas nos discursos das revistas Veja e Carta Maior, por meio de duas colunas opinativas, em relação ao atentado contra o periódico satírico francês Charlie Hebdo, ocorrido no início de 2015, bem como os efeitos de sentidos gerados por elas. Ao todo, são analisadas seis sequências discursivas, sendo três de cada uma das colunas. Para tanto, são mobilizados os conceitos de Formação Discursiva e Silenciamento, com base nos estudos de autores como Pêcheux (2009; 2010; 2011) e Orlandi (2007; 2010; 2011). Além disso, são tecidas considerações sobre o funcionamento do discurso jornalístico, a partir dos estudos de Mariani (1998) e Gregolin (1995; 1997), em especial no que tange à imagem de autoridade passada pela mídia. O ataque à revista francesa teve repercussão mundial por incitar ainda mais o debate sobre assuntos historicamente polêmicos: religião, liberdade de imprensa e imigração. As revistas Veja e Carta Maior, por se inscreverem em formações discursivas distintas, não apontaram as mesmas causas para o atentado. Nesse sentido, o trabalho se faz relevante por buscar compreender como se deu a construção discursiva no que tange às causas do ataque, em dois veículos de comunicação com posições ideológicas distintas, e dar abertura a novas discussões sobre a temática.

Palavras-chave: Análise do Discurso. Veja. Carta Maior.

\section{ABSTRACT}

This paper aims, in the light of the French school of Discourse Analysis theory, to identify, by examining two opinionative columns, Veja's and Carta Maior's alignment to the attack to the satiric French periodical Charlie Hebdo, occurred in January 2015, as well as the sense effects caused by them. Six discursive sentences are analyzed, being three from each column. In order to do so, the concepts of discursive formation and silencing are used, based on the studies by authors such as Pêcheux $(2009 ; 2010 ; 2011)$ and Orlandi $(2007 ; 2010 ; 2011)$ ). Also, considerations regarding the operation of journalistic discourse are developed, based on theoreticians such as 
Mariani (1998) and Gregolin (1995; 1997), specially regarding the authoritarian image conveyed by media. The attack to the French magazine had worldwide repercussion, further prompting the debate regarding historically controversial issues such as religion, press freedom and imigration. Veja and Carta Maior magazines, by subscribing to different discourse formations, did not point to the same supposed motives for the attack. Thereby, this paper is made relevant for its attempt to understand how the discursive building, regarding the causes of the attack, was developed in two media vehicles with very distinct ideological positions, as well as to open new discussions on the subject.

Keywords: Discourse Analysis. Veja. Carta Maior.

\section{CONSIDERAÇÕES INICIAIS}

Ao longo do tempo, religiosos e imigrantes foram causa e alvo de ataques, de censura e de violência física e moral. Tal histórico ocasionou a associação desses grupos sociais à polêmica, pois o embate de pontos de vista distintos, por vezes, transforma-se em agressividade e opressão. Mas não é apenas a população em falas e atos individuais que reproduz o pensamento intolerante: alguns veículos de comunicação reservam parte de seus espaços opinativos para publicações com caráter provocativo e hostil, afrontando ideologias às quais são contrários.

O semanário francês Charlie Hebdo é um exemplo desses veículos. Publicado semanalmente, o periódico surgiu na década de 1970. De caráter satírico, tece críticas de cunho político, cultural, econômico e religioso por meio de caricaturas, piadas e artigos. Parte das publicações é direcionada a criticar as mais diversas religiões, especialmente o catolicismo, o islamismo e o judaísmo, o que não é bem aceito pelos religiosos. Ao se depararem com caricaturas representando de forma pejorativa o Profeta Maomé, alguns muçulmanos, em forma de protesto e revolta, entraram com processo judicial contra a revista francesa em 2006. Mesmo assim, os cartunistas não mudaram de postura e continuaram a retratar a imagem do Profeta, o que acarretou em ataques com bombas à sede do semanário nos anos de 2011 e 2012.

Diante dos atentados, os cartunistas passaram a ter proteção policial, mas as charges continuaram sendo veiculadas. Em 7 de janeiro de 2015, radicais do Estado Islâmico novamente atacaram o periódico; desta vez, em um tiroteio, mais de 10 pessoas morreram, entre jornalistas e policiais. $\mathrm{O}$ atentado deixou a França em estado de alerta e teve repercussão mundial, uma vez que envolvia três temas considerados complexos e delicados: religião, imigração e liberdade de imprensa. 
O acontecimento instantaneamente tornou-se notícia no Brasil, mas os veículos de comunicação se posicionaram de forma diferente em relação ao ocorrido: enquanto alguns alegavam que o semanário Charlie Hebdo apenas fez uso da liberdade de imprensa, outros criticaram as charges publicadas, deixando claro que o periódico não tinha direito de incitar essas provocações. Assim, da mesma forma que uma palavra apresenta sentidos distintos conforme quem a emprega e em que contexto é empregada, o mesmo acontecimento ganha sentidos diferentes de acordo com a Formação Discursiva (FD) que o interpreta e avalia.

Dessa forma, o corpus desta pesquisa é constituído por duas colunas jornalísticas que representam as diferentes posições assumidas pela mídia brasileira: uma escrita por Rafo Saldanha, publicada no blog de Leonardo Boff, na revista eletrônica Carta Maior, em 10 de janeiro de 2015, que criticou a forma com que o semanário abordava a temática religiosa, e outra escrita por Ricardo Setti, publicada no portal da revista Veja, em 07 de janeiro de 2015, que aparenta ver o fato como decorrente do uso da liberdade de imprensa, apontando a imigração indiscriminada como causa do ataque.

A Carta Maior é uma revista eletrônica que se autodenomina "Portal de Esquerda". Foi fundada em 2001, em Porto Alegre, juntamente com a primeira edição do Fórum Social Mundial ${ }^{1}$. É um veículo que defende a democratização da mídia e do Estado brasileiro e objetiva contribuir com o fortalecimento da integração sul-americana. $\mathrm{O}$ foco da revista são os direitos humanos, o meio ambiente, a política, a economia e os movimentos sociais.

Já a Veja foi fundada em 1969 e é publicada pela Editora Abril semanalmente. Aborda política, economia, cultura, tecnologia, ciência, ecologia e religião. É a revista brasileira de maior circulação nacional, uma vez que são impressas mais de um milhão de cópias de cada edição. De acordo com Zanella (2012), a linha editorial do periódico é baseada no neoliberalismo, doutrina que adota os valores políticos e econômicos do capitalismo e defende a não participação do estado na economia.

Os dois veículos de comunicação apresentados são ideologicamente distintos, o que é visível pelos posicionamentos adotados quanto ao atentado, bem como pelos objetivos editoriais. Uma vez que a imprensa é formadora de opinião, faz-se necessário o estudo de publicações, especialmente das que abordam temas polêmicos, pois os sentidos construídos a partir desses textos interferem no posicionamento da população em relação ao assunto. Ressalta-se, todavia, que a presente pesquisa visa investigar o processo de construção de sentido ensejado pelas publicações, não o efeito que esses sentidos teriam em seus leitores. Além da importância social, esta pesquisa se faz pertinente pelo âmbito científico, pois, enquanto há um vasto acervo de trabalhos sobre a Veja, não há produções sobre a Carta Maior. Além disso, a necessidade de desconstruir mitos como neutralidade, imparcialidade e objetividade no jornalismo também justifica esta pesquisa. 
A proposta deste trabalho, diante do exposto, é compreender, à luz da Análise do Discurso de linha francesa (doravante, AD), as condições de produção das colunas, que englobam o contexto histórico/ideológico em que foram construídas, identificar a forma como os dizeres são apresentados e por que foram apresentados, entender como são construídos os discursos (considerando quem os construiu e o momento em que foram produzidos) e quais os efeitos de sentido gerados nessa construção.

Assim, considerando os dois colunistas como sujeitos pertencentes a FDs distintas, bem como as condições de produção em cada um dos veículos de comunicação, busca-se, com esta pesquisa, investigar como ocorre a construção de efeitos de sentido a partir do que é dito e do que é silenciado, uma vez que o não dito significa tanto quanto os dizeres explícitos nas colunas, especialmente por tornar ainda mais perceptíveis os embates entres as FDs.

\section{ANÁLISE DO DISCURSO: ORIGENS E DESDOBRAMENTOS}

Surgida na França, na década de 1960, a partir da confluência entre Linguística, Psicanálise (mais especificamente, da releitura de Freud feita por Lacan) e Materialismo Histórico (por meio de uma leitura althusseriana de Marx), com os estudos de Michel Pêcheux, a AD é uma teoria de leitura e interpretação que se propõe a ir além da análise textual: o contexto histórico, as condições de produção e, especialmente, a ideologia são fatores substanciais para a análise discursiva. Assim, compreende-se que o âmbito extralinguístico revela dados indispensáveis para a teoria e para o olhar sob o corpus. A AD, então, é considerada uma disciplina de entremeio e, nesse sentido, Orlandi (2007) reforça que ela

\footnotetext{
interroga a Lingüística pela historicidade que ela deixa de lado, questiona o Materialismo perguntando pelo simbólico e se demarca da Psicanálise pelo modo como, considerando a historicidade, trabalha a ideologia como materialmente relacionada ao inconsciente sem ser absorvida por ele (ORLANDI, 2007, p. 20).
}

$\mathrm{Na}$ época de seu surgimento, um período de turbulência política e econômica, de descontentamento estudantil e de greve dos trabalhadores assolava a França. Em meio a esse cenário, foi despertada no âmbito científico a necessidade de um novo mecanismo de análise, "numa tentativa de fazer com que a Linguística contribuísse com a ciência da ideologia, eliminando os postulados idealistas da Semântica" (ORSATTO, 2014, p. 15). Assim, a AD originou-se. A teoria teve seu início ao romper com estudos que não respondiam aos questionamentos levantados (quem diz, por que diz, como diz): com a linguística, cuja análise se baseava na língua apenas enquanto estrutura; com a análise de conteúdo, que via o sentido sendo 
originado de dados contidos nos textos; e com a filologia, com a ideia de que há uma só interpretação possível nos textos. A AD objetiva compreender o entorno textual e "visa a compreensão de como um objeto simbólico produz sentidos, como ele está investido de significância para e por sujeitos" (ORLANDI, 2010, p. 26).

Em seu trajeto histórico, o desenvolvimento da AD é marcado por três fases: a AAD 1969 (Análise Automática do Discurso), a AD 1975 e a AD 1983. Pêcheux inaugurou a primeira fase com a publicação do livro Análise Automática do Discurso. Nessa fase, o sujeito é visto como assujeitado, o que significa dizer que o sujeito não fala por si, mas pelas instituições a que pertence. Além disso, surge o conceito de máquina discursiva, que corresponde à noção de que há uma estrutura que gera o processo discursivo. Dito de outra forma, esse processo é oriundo desta máquina discursiva, fechada em si mesma, "de tal modo que um sujeito-estrutura determina os sujeitos como produtores de seus discursos: os sujeitos acreditam que ‘utilizam' seus discursos quando na verdade são seus 'servos' assujeitados, seus 'suportes”" (PÊCHEUX, 2010, p. 307).

Em seguida, surge o conceito de condições de produção, que foi se transformando ao longo das fases da $\mathrm{AD}$ e ocupa lugar relevante nas análises discursivas até os dias de hoje, engloba aspectos históricos, permitindo compreender melhor por que um enunciado foi dito em detrimento de outro, já que há razões determinadas tanto pelo entorno imediato quanto pelo contexto em termos mais amplos (o que engloba o social, o histórico, o ideológico):

As condições de produção, que constituem os discursos, funcionam de acordo com certos fatores. Um deles é o que chamamos de relação de sentidos. Segundo essa noção, não há discurso que não se relacione com outros. Em outras palavras, os sentidos resultam de relações: um discurso aponta para outros que o sustentam, assim como para dizeres futuros. Todo discurso é visto como um estado de um processo discursivo mais amplo, contínuo. Não há, desse modo, começo absoluto nem ponto final para o discurso (ORLANDI, 2010, p. 39).

Na segunda fase da $\mathrm{AD}$, a $\mathrm{AD} 75$, o conceito de máquina discursiva começa a ser desconstruído: a FD, conceito cunhado por Foucault, que remete às condições de exercício da função enunciativa, ou seja, aquilo que delimita o que pode ser proferido dentro de um contexto histórico-social, não é mais sinônimo de maquinaria discursiva. Nessa fase, destaca-se que se compreende uma FD como sempre invadida por elementos de outras FDs e se constituindo no embate com outras FDs. Enquanto na AAD 69 valorizava-se o intradiscurso, a AD 75 passa a valorizar a relação entre as FDs. Nesse ínterim, o objeto da AD 75 passa a ser as relações entre as máquinas discursivas. Em relação aos procedimentos de análise, não há grandes mudanças de uma fase para a outra, mas os discursos analisados apresentam menos estabilidade e menos homogeneidade. 
Além disso, surge a noção de esquecimento n. 1 e de esquecimento n. 2. Chamada pela AD também como esquecimento ideológico, da ordem do inconsciente, o esquecimento n. 1 é a ilusão do sujeito de ser origem do que diz, por não ter consciência de seu assujeitamento. Já o esquecimento n. 2é a crença do sujeito de escolher/selecionar o que diz, com a ilusão de que não há outra forma de o fazer e de que possui controle sobre o sentido do dizer:

\begin{abstract}
Concordamos em chamar esquecimento n. 2 ao 'esquecimento' pelo qual todo sujeito-falante 'seleciona' no interior da formação discursiva que o domina, isto é, no sistema de enunciados, formas e sequências que nela se encontram em relação de paráfrase - um enunciado, forma ou sequência, e não um outro, que, no entanto, está no campo daquilo que poderia reformulá-lo na formação discursiva considerada. Por outro lado, apelamos para a noção de 'sistema inconsciente' para caracterizar um outro 'esquecimento', o esquecimento $n$. 1 , que dá conta do fato de que o sujeito-falante não pode, por definição, se encontrar no exterior da formação discursiva que o domina (PÊCHEUX, 2009, p. 161).
\end{abstract}

$\mathrm{Na}$ terceira fase da $\mathrm{AD}$, tem-se a concepção de que os discursos são construídos no interdiscurso e não dentro de uma FD, como se acreditava anteriormente. Nesse contexto, o procedimento de análise que, desde a primeira fase, era dividido por etapas, seguindo uma ordem, é desconstruído. É a partir da noção de interdiscurso que, na AD 83, o conceito de heterogeneidade é concebido por Authier-Revuz, o que significa dizer que há a presença de diferentes vozes em um discurso.

Objeto sócio-histórico de estudo da AD, o discurso, segundo Orlandi (2007), é caracterizado como palavra em movimento, língua em funcionamento. Dessa forma, ressalta-se que o discurso é materializado pela língua, mas permeado por fatores históricos, ideológicos e sociais. Por isso, de acordo com Pêcheux (2011, p. 128), "o processo do discurso não deve, evidentemente, ser confundido com ato de fala do sujeito falante individual", nem ser considerado apenas sob aspectos linguísticos.

Orlandi (2010, p. 20) ressalta que "o sujeito de linguagem é descentrado pois é afetado pelo real da língua e também pelo real da história, não tendo o controle sobre o modo como elas o afetam. Isso redunda em dizer que o sujeito discursivo funciona pelo inconsciente e pela ideologia", isto é, o sujeito não dissemina discursos por sua livre escolha. Para a AD, o discurso é a materialização da ideologia, pois, segundo Orlandi (2010), é a partir dela que se dá a constituição de sentidos e a possibilidade de interpretação.

Para Orlandi (2010, p. 50), "se ele [o sujeito] não se submeter à língua e à história, ele não se constitui, ele não fala, não produz sentidos”, pois os sentidos não se encontram no sujeito nem nas palavras em si mesmas, uma vez que "as palavras podem mudar de sentido segundo as posições sustentadas por aqueles que as empregam” (PÊCHEUX, 2011, p. 64), já que, ainda segundo o autor, é a ideologia que faz com que um enunciado queira dizer o que diz. 
Para a $\mathrm{AD}$, o silêncio também gera efeitos de sentidos e possibilita várias interpretações. Para Orlandi (2007, p. 90), "é no silêncio que as diferentes vozes do sujeito se entretecem em uníssono. Ele é o amálgama das posições heterogêneas"; a autora complementa afirmando que "o silêncio é assim a "respiração" (o fôlego) da significação, um lugar de recuo necessário para que se possa significar, para que o sentido faça sentido (ORLANDI, 2007, p. 13).

O silêncio não indica uma ausência para a AD; pelo contrário, pois, para Orlandi (2007, p. 68), “o silêncio não é vazio, ou sem sentido, [...] ele é o indício de uma instância significativa. Isso nos leva à compreensão do 'vazio' da linguagem como um horizonte e não como um falta".

No que tange ao interdiscurso, Pêcheux (2009) o define como o todo complexo com dominante das FDs, ou seja, é o conjunto das FDs. Já o intradiscurso é "o funcionamento do discurso com relação ao que eu disse antes e ao que eu direi depois; portanto, o conjunto dos fenômenos de 'co-referência' que garantem aquilo que se pode chamar o 'fio do discurso', enquanto discurso que vem de um sujeito" (PÊCHEUX, 2009, p. 153). Assim, o intradiscurso é a formulação do discurso, aquilo que se está dizendo, enquanto o interdiscurso é o já-dito, que não vem (só) de uma FD ou da FD em que o sujeito se inscreve.

Outro conceito relacionado ao interdiscurso é o de memória discursiva, que, para Pêcheux (1999, p. 52), é aquilo que "face a um texto que surge como acontecimento a ler, vem estabelecer os 'implícitos' (quer dizer, mais tecnicamente, os pré-construídos, elementos citados e relatados, discursos transversos, etc.) de que sua leitura necessita: a condição do legível em relação ao próprio legível". Nesse sentido, o efeito de sentido não vem de um enunciado, mas de uma relação deste com outros enunciados já formulados, já materializados, ou seja, da memória discursiva. Assim, todo discurso é construído a partir de uma memória.

As colunas opinativas que interessam a este trabalho carregam, no discurso que disseminam, memórias em relação à polêmica que envolve a imigração e a religião muçulmana, bem como discussões sobre o que de fato representa a liberdade de imprensa, uma vez que cada um dos veículos de comunicação se posicionou de uma forma no que tange aos direitos de publicação do semanário Charlie Hebdo.

\section{JORNALISMO E DISCURSO}

Olhar o jornalismo sob uma perspectiva discursiva é perceber que o texto jornalístico é um mosaico de discursos, pois incorpora enunciados de várias instituições para se constituir, o que o torna um campo profícuo de análise para a AD. Assim, para Gregolin (2007), 
a análise do discurso, campo de pesquisa solidamente instalado no Brasil, interessa-se cada vez mais em tomar a mídia como objeto de investigação. A articulação entre os estudos da mídia e os de análise do discurso enriquece dois campos que são absolutamente complementares, pois ambos têm como objeto as produções sociais de sentidos (GREGOLIN, 2007, p. 13).

Uma das responsabilidades do jornalismo é transmitir à população, por meio dos veículos de comunicação, aquilo que ocorre a nível local, regional, nacional e internacional, a partir dos chamados critérios de noticiabilidade, que priorizam a publicação de alguns fatos em detrimento de outros. O ato de noticiar, por vezes tomado como imparcial, de acordo com Mariani (1998), não é desinteressado nem mesmo neutro, já que nele se encontram interesses ideológicos do jornal, do repórter, dos anunciantes e até mesmo dos leitores.

Por tornar públicos os fatos, há a associação entre o discurso jornalístico, a notícia, por exemplo, e veracidade, como se o jornalismo fosse detentor da verdade e, consequentemente, publicasse apenas o que de fato aconteceu, exatamente como aconteceu. Contudo,

\footnotetext{
comunicar/informar/noticiar (na imprensa) são atos resultantes de um controle exterior, vindo do Estado e do sistema jurídico por um lado, e, por outro, de um controle internalizado na própria atividade jornalística. Os efeitos ilusórios estão aí: o controle externo e interno, garantindo a objetividade (e neutralidade etc.), garantiria também a imprensa como digna de fé (MARIANI, 1998, p. 73).
}

Por isso, criou-se em torno das atividades jornalísticas a ilusão da imparcialidade, como se o controle externo e o interno, como citados por Mariani (1998), garantissem que as notícias publicadas fossem verdadeiras, retratos da realidade, atestando credibilidade à imprensa. Não é raro ouvir a expressão "saiu no jornal, então é verdade", o que comprova a ideia equivocada atribuída à mídia por parte da população.

Isso também ocorre porque, segundo Navarro (2006), o discurso jornalístico é uma prática reconhecida pela sociedade como discurso autorizado. Assim, o jornalismo, por ser produtor e difusor de cultura, construiu uma imagem de confiança, o que gerou confiabilidade aos jornalistas e a noção de que tudo o que é escrito/dito por eles é verdadeiro e imparcial, o que é desmitificado pela Análise do Discurso.

Para Mariani (1998, p. 61), “o discurso jornalístico contribui na constituição do imaginário social e na cristalização da memória do passado, bem como na construção da memória do futuro", já que, ao produzir um texto, o profissional de jornalismo procura levar em consideração tudo aquilo que outrora foi dito, isto é, busca ativar a memória discursiva para mostrar que sua publicação está interligada a enunciados prévios, o que já foi dito em outro lugar, com o objetivo de gerar sentido para quem lê, mesmo que não seja possível controlar os efeitos de sentido gerados. 
Contudo, de acordo com Bakhtin (1999), o interlocutor contribui com a construção de sentidos por meio daquilo que o autor chama de princípio da responsividade ativa: toda compreensão é uma resposta, ou seja, a resposta não é vista como réplica de uma pergunta, mas como posicionamento ideológico mesmo que interno. Nesse ínterim, tanto o jornalista quanto o leitor são responsáveis pelo sentido do discurso jornalístico, uma vez que, ao ler uma reportagem, o interlocutor se posiciona ideologicamente. Dessa forma, “o sentido, no jornal, constitui-se como um diálogo em três dimensões: o sujeito da escrita, o destinatário e os textos exteriores" (GREGOLIN, 1997, p. 10). Com isso, reitera-se que os efeitos de sentido não se encontram no texto, mas são uma construção.

\section{LIBERDADE DE IMPRENSA OU INTOLERÂNCIA? O DISCURSO DA VEJA E DA CARTA MAIOR}

Por meio do discurso, é possível observar a relação existente entre ideologia, língua e condições de produção. As colunas opinativas selecionadas como corpus, cujo tema é construído a partir dos assuntos religião, imigração e liberdade de imprensa, historicamente tidos como polêmicos, são exemplos dessa constatação.

Nesse sentido, o objetivo desta seção é analisar o corpus da pesquisa. Para tanto, ele será dividido em duas subseções: na primeira, será feita a análise das duas SDs extraídas da coluna opinativa escrita por Ricardo Setti, publicada na Veja; na segunda, a análise realizada será da coluna escrita por Rafo Saldanha, publicada no blog de Leonardo Boff no portal da Carta Maior.

\subsection{CASO CHARLIE HEBDO: REPERCUSSÃO NA VEJA}

A Veja é a revista de maior circulação nacional. Em seu portal online, há publicações extras, como colunas opinativas. Um dos colunistas, o jornalista Ricardo Setti, publicou, no dia 7 de janeiro de 2015, um texto sobre o atentado ao periódico Charlie Hebdo, sob o título "Ataque covarde e sanguinário contra semanário satírico Charlie Hebdo na França é o maior atentado contra a imprensa na Europa desde a II Guerra Mundial - e infelizmente deve reforçar o sentimento anti-islâmico e anti-imigrantes na União Europeia”.

Já pelo título, identifica-se a defesa à liberdade de imprensa por parte da FD em que Setti se insere, bem como a menção de dados sobre as manifestações anti-imigrantes na Europa, aspecto não abordado pela coluna de Rafo Saldanha, na Carta Maior, como será visto na próxima subseção. 
Ricardo Setti inicia seu texto caracterizando de forma negativa o ataque contra $o$ semanário Charlie Hebdo, como é possível identificar na primeira SD.

SD 1: O cruel e covarde ataque de fanáticos assassinos muçulmanos contra o semanário satírico francês Charlie Hebdo [...] já é considerado o maior atentado contra a imprensa livre desde a II Guerra Mundial na Europa. Infelizmente, os criminosos partidários da barbárie e absolutamente incapazes de conviver com qualquer tipo de liberdade de expressão que, em sua visão distorcida, possa ferir dogmas nos quais acreditam — como os autores desse atentado -, só vêm reforçar o crescente sentimento antiislâmico na Europa que, por extensão, se estende e acaba se confundindo com uma forte hostilidade a imigrantes em geral.

É possível perceber pela SD1 o posicionamento de Veja, que chamaremos de a favor da liberdade de expressão, visto que, de acordo com o discurso disseminado por Setti, sátiras em relação à fé não são consideradas ofensivas, pois todos têm o direito de expressar opiniões livremente. Para Veja, o ataque foi considerado cruel e covarde. Um dos sentidos para o termo covardia é atacar aquele que não pode se defender, que utiliza força para prejudicar injustamente outras pessoas. Nesse sentido, pode-se inferir que os cartunistas foram atacados injustamente e estavam indefesos no momento da agressão.

O colunista chama os muçulmanos responsáveis pelo atentado de fanáticos, termo associado ao excesso de admiração/zelo (no caso, pela crença), que, para a FD que atravessa o discurso da Veja, apresenta caráter negativo, pois, para tal FD, fanáticos buscam moldar a opinião do outro de acordo com a sua própria e o fazem de forma impositiva, especialmente em relação a questões religiosas, uma vez que o sentido da palavra não está nela mesma, mas é construído ideologicamente e varia de acordo com a FD. Com isso, Setti demonstra a não concordância da FD com a censura às charges/caricaturas publicadas em provocação à religião islâmica, pois, se não houvesse fanatismo por parte dos muçulmanos, não existiriam problemas em utilizar a imagem do profeta Maomé da forma como foi utilizada.

Ressalta-se, no entanto, que é silenciado pela FD o fato de que, para os muçulmanos, seres sagrados não podem ter sua imagem representada, pois, de acordo com o Corão, a idolatria de representações é errado: para a religião Islâmica, as imagens de profetas e de Deus devem existir apenas na imaginação dos fiéis, já que o que importa, para o Islamismo, são os ensinamentos e a preservação da figura do profeta. Tal silenciamento ocorre pois, para a FD, o repúdio à representação do profeta caracteriza uma atitude de fanáticos.

O fervor das crenças é repudiado pelo discurso de Veja, e há a repetição desse repúdio, por meio de paráfrases, para que o efeito de sentido seja reforçado, como nos trechos "cruel e covarde ataque de fanáticos assassinos", "[...] pregação radical de clérigos em mesquitas país afora" e também a generalização feita quando o colunista afirma que os seguidores do Islã são 
“incapazes de conviver com qualquer tipo de liberdade de expressão", o que, ainda segundo a $V e j a$, reforça o sentimento anti-islâmico. Contudo, em momento algum a possibilidade de as publicações do Charlie Hebdo gerarem um sentimento anti-islâmico é citada pelo colunista. Assim, é possível identificar o silenciamento da Veja em relação às consequências sociais das publicações do semanário francês.

Para Orlandi (2007), uma palavra apaga outras possíveis, uma vez que, para dizer é preciso não dizer, já que se diz X e deixa-se de dizer Y. Nesse caso, Veja, ao não dizer que as publicações geraram ideias discriminatórias em relação aos muçulmanos como feito pelo extremismo dos religiosos, procura fazer com que o leitor de sua coluna acredite que a liberdade de expressão deve ser total, independentemente do conteúdo publicado.

Retomando o comentário de que os muçulmanos são "incapazes de conviver com qualquer tipo de liberdade de expressão”, pode-se inferir que há novamente uma generalização: os muçulmanos não foram incapazes de conviver com qualquer tipo de liberdade de expressão, mas foram incapazes de conviver com a liberdade de expressão que gerou ofensas à crença islâmica. Nesse trecho, nota-se a diferente construção de sentido para a expressão "liberdade de expressão": para a $V e j a$, que se posiciona a favor, a liberdade se mostra no ato de falar o que se quer, da forma como se quer. Já para a Carta Maior, com posicionamento contrário à total liberdade de expressão, como será visto de forma mais aprofundada na próxima seção de análise, a liberdade, quando extrapola o limite, passa a ser ofensa por atingir a crença do outro, desrespeitando-a. Isso ocorre já que "o sentido de uma sequência só é materialmente concebível na medida em que se concebe esta sequência como pertencente necessariamente a esta ou aquela formação discursiva (o que explica, de passagem, que ela possa ter vários sentidos)" (PÊCHEUX; FUCHS, 1993, p. 167).

Para a FD em que Setti se inscreve, liberdade de imprensa e liberdade de expressão são tomadas como equivalentes. Com isso, nota-se o efeito metafórico que ocorre no interior de uma FD, em que um termo equivale a outro. Diante disso, faz-se relevante diferenciar liberdade de expressão e liberdade de imprensa: esta garante aquela. A liberdade de imprensa é caracterizada pela não interferência do Estado nas publicações da mídia, mas, mesmo assim, há uma lei que visa a regulamentar as práticas jornalísticas.

A lei de liberdade de imprensa da França é a mais antiga em vigor, datada de 29 de julho de 1881. Nela, a liberdade de expressão é prevista, mas o incitamento a cometer crimes, discriminação, ódio ou violência é condenado. Sendo que discriminação pode ser entendida como o ato de prejudicar o outro em um contexto social, cultural, político ou econômico, as publicações da Charlie Hebdo tinham caráter discriminatório, o que vai contra a lei de liberdade de imprensa francesa. Assim, pode-se afirmar que Veja, mais uma vez, silencia dizeres em seu discurso: neste caso, em relação às leis francesas de liberdade de imprensa. 
$\mathrm{Na}$ coluna em questão, assim como em todo discurso, há o funcionamento dos esquecimentos $\mathrm{n}^{\mathrm{o}} 1$ e $\mathrm{n}^{\mathrm{o}} 2$, visto que revela um sujeito que não consegue reconhecer a opacidade do que diz, além de deixar evidente que acredita ser apenas essa a forma de dizer o que foi dito por ele, como acontece na próxima SD em relação aos movimentos anti-imigrantes.

SD 2: Em geral muito pouco qualificados profissionalmente, com dificuldades imensas para adaptar-se à cultura ocidental e para aprender o idioma, essas pessoas, majoritariamente muçulmanas, acabam permanecendo indefinidamente no país graças a grupos de pressão vários, inclusive defensores dos direitos humanos, dificultando a adoção de políticas de imigração dos governos destinadas a preencher necessidades específicas da sociedade.

Para a Veja, os imigrantes que, segundo a revista, são majoritariamente muçulmanos (mas não são mencionados fontes ou dados estatísticos), são pouco qualificados profissionalmente, não se adaptam facilmente à cultura ocidental e têm dificuldades de aprender o idioma. Contudo, a voz dos próprios imigrantes é silenciada, já que a FD se posiciona e fala sobre eles, mas não abre espaço para que eles falem sobre como é se adaptar a um novo país.

Além disso, outros aspectos não ditos por Veja são algumas das causas da dificuldade de adaptação por parte dos imigrantes, como a hostilidade de muitos nativos, o preconceito e a falta de oportunidade de ascensão profissional, pois a revista é atravessada por um imaginário em que essas não são as causas, mas sim as consequências pelos imigrantes estarem em um país cuja cultura é tão distinta da cultura deles. Segundo Zanella (2012), "todo esse atravessamento em Veja tem base numa FD neoliberal”, e, com isso, Veja realça o pré-construído de que, quanto mais qualificado profissionalmente, mais respeito a pessoa "merecerá".

O discurso da Veja é de que os grupos que defendem os direitos dos imigrantes dificultam a adoção de políticas de imigração que preencheriam necessidades específicas da sociedade, isto é, de que a culpa dos imigrantes permanecerem no país é dos direitos humanos, que pressionam o governo. Entretanto, as necessidades citadas são da sociedade nativa, não dos imigrantes. Assim, Veja, por meio de paráfrases, reforça o posicionamento de que a imigração não deve ser legalizada ou aceita em qualquer situação, mas deve se restringir a atender as necessidades do país, já que "a produção do sentido é estritamente indissociável da relação de paráfrase entre sequências tais que a família parafrástica destas sequências constitui o que se poderia chamar a "matriz do sentido"” (PÊCHEUX; FUCHS, 1993, p. 167).

Ressalta-se que a Veja não desvaloriza tudo o que é estrangeiro: ela desvaloriza apenas o que não é hegemônico e desvaloriza populações consideradas incultas e fanáticas. Em contrapartida, a mão de obra desses imigrantes é vista como útil. Nesse sentido, a FD não é favorável à legalização desses imigrantes, mas a imigração ilegal apresenta benefícios, como é 
possível perceber em outras publicações da Veja. Em 25 de setembro de 2015, o jornalista Leonardo Narloch publicou no portal da revista o texto "A livre imigração é uma bandeira da esquerda ou da direita?". Abaixo, segue um trecho:

\begin{abstract}
Milton Friedman, o pai do neoliberalismo, defendia a imigração - mas não qualquer tipo de imigração, apenas a ilegal. 'É uma coisa boa ter imigrantes ilegais', ele dizia. 'É bom para os Estados Unidos. É bom para os cidadãos do país. Mas só é bom se for imigração ilegal'. Friedman acreditava que a imigração legal é incompatível com o estado de bem-estar social: é preciso escolher um dos dois. [...] A imigração em massa sabota diversas bandeiras da esquerda. Aumenta a estatística de desigualdade, pressiona para baixo o salário de trabalhadores pouco qualificados, enfraquece os sindicatos e diminui a aceitação do povo a políticas de transferência de renda. [...] Ao se opor à imigração, a direita brasileira cai na caricatura que a esquerda tenta lhe atribuir. Dá munição à ideia de que 'a direita é contra os pobres'. Não, a direita não é contra os pobres, mas contra os pobres que querem ganhar dinheiro pela expropriação, e não pelo esforço próprio. Não é o caso dos imigrantes (NARLOCH, 2015).
\end{abstract}

Assim, o discurso da Veja de que os imigrantes ilegais buscam trabalho e, com isso, contribuem com a economia do país para o qual imigraram, ou seja, a imigração é benéfica, quando atende a interesses internos, é disseminado em suas publicações. De acordo com Zanella (2012, p. 62), a Veja afirma e reafirma "a importância da qualificação profissional, transferindo a responsabilidade do desemprego ao próprio desempregado, como se o 'problema' da não qualificação profissional fosse daquele que não corre atrás de um grau acadêmico ou profissionalizante". Nesse ínterim, os direitos dos imigrantes são silenciados pela FD, para a qual os imigrantes devem apenas trabalhar e ganhar dinheiro por esforço próprio, sem oportunidades de melhores empregos, para sobreviverem.

\title{
4.2 CASO CHARLIE HEBDO: REPERCUSSÃO NA CARTA MAIOR
}

A Carta Maior, que se autodenomina como "Portal de Esquerda", possui mais de 40 colunistas. O teólogo Leonardo Boff é um deles e publicou em sua coluna no periódico, no dia 10 de janeiro de 2015, um texto de autoria do jornalista Rafo Saldanha sobre o atentado de Paris, intitulado "Je ne suis pas Charlie", demonstrando posicionamento contrário às publicações do semanário francês, uma vez que, logo após o ataque, pessoas do mundo inteiro publicaram na internet mensagens com a frase "Je suis Charlie", em homenagem aos cartunistas vítimas do atentado. É possível inferir que Boff e Saldanha se inscrevem em uma mesma FD, que condiz com a linha editorial da Carta Maior, o que explica, de certa forma, o fato de Boff ter publicado um texto que não é de sua autoria em sua coluna. Na SD 3, é possível perceber convergências entres os discursos da Veja e da Carta Maior, já que está presente no interdiscurso a ideia de que a vida humana deve ser respeitada, sendo, então, inaceitável e injustificável cometer assassinatos, como percebido pelas SDs retiradas da Veja e pela SD a seguir: 
SD 3: Não acho que nenhum dos cartunistas 'mereceu' levar um tiro. Ninguém merece. A morte é a sentença final, não permite que o sujeito evolua, mude. Em momento nenhum, eu quis que os cartunistas da Charlie Hebdo morressem. Mas eu queria que eles evoluíssem, que mudassem.

Além disso, por meio dessa SD, é possível perceber a mobilização de uma FD que chamaremos de crist $^{4}$, pois o colunista afirma que a morte é a sentença final, o que não possibilita a evolução e a mudança, fazendo referência ao sexto dos dez mandamentos cristãos, "não matarás", dando a entender que nenhum erro, inclusive o desrespeito às religiões, é passível de morte.

Identifica-se também a relação existente com a passagem bíblica cuja mensagem é de que todo pecado será perdoado, exceto o pecado contra o Espírito Santo. Segundo uma das análises cristãs da Bíblia, o pecado contra o Espírito Santo refere-se ao arrependimento: todo pecador arrependido será perdoado. Assim, infere-se que a mudança/evolução a que Saldanha faz referência é o arrependimento dos cartunistas por terem ofendido os muçulmanos, ou seja, eles deveriam continuar vivos para terem a chance de se arrependerem, se redimirem; assim, para a FD cristã, eles estariam evoluindo.

A posição de Saldanha enquanto sujeito que não crê em outras vidas/encarnações é também identificada, pois coloca a morte como sendo a sentença final (pelo menos para a matéria, para o corpo). É pertinente observar que o islamismo acredita que Alá trará de volta à vida todos os mortos no último dia, para que seja feito o julgamento e, então, ter uma nova vida iniciada. Assim, a FD cristã demonstra apoio à defesa da imagem do profeta Maomé por respeito, mas não assume para si os princípios da religião muçulmana. Pode-se inferir que esse apoio também foi motivado pela revolta às charges de Cristo, também veiculadas pelo periódico Charlie Hebdo, que provocaram/ofenderam muitos cristãos. Além disso, o cartunista francês conhecido como Charb, em uma declaração pública, afirmou ser necessário que o Islã ficasse tão banalizado quanto o catolicismo, o que indignou tanto cristãos como muçulmanos.

O termo "mereceu", entre aspas, é um exemplo de heterogeneidade mostrada. Com o uso das aspas, revela-se a responsabilidade que o locutor não deseja ter para si, por isso, tenta se eximir utilizando as aspas. Nesse termo, o sentido se apresenta no que tange à afirmação de que os cartunistas de fato mereceram morrer: alguém o pode afirmar, mas não é um dizer que faz parte do discurso da Carta Maior, considerando que iria de encontro aos direitos humanos a defesa de um assassinato. Devido ao efeito do esquecimento, o autor tem a ilusão de escolher a palavra e de ter controle pelo sentido que pode gerar - no caso, uma tentativa de justificar que, por mais que seja contra os atos dos cartunistas, não era favorável à morte. Além disso, a negação também denuncia o jogo com a outra voz/o outro posicionamento a que o autor quer se contrariar. 
SD 4: Ontem vi Ziraldo chamando os cartunistas mortos de 'heróis'. O Diário do Centro do Mundo (DCM) os chamou de 'gigantes do humor politicamente incorreto'. No Twitter, muitos chamaram de "mártires da liberdade de expressão". Vou colocar na conta do momento, da emoção. As charges polêmicas do Charlie Hebdo são de péssimo gosto, mas isso não está em questão.

Nessa segunda SD, outras vozes são acionadas por Saldanha (Ziraldo, DCM e usuários do twitter), que apresentam discurso contrário ao posicionamento defendido, o que gerou um efeito contra-argumentativo no texto, pois são oriundas de uma FD diferente da FD que Saldanha atualiza em suas práticas discursivas: enquanto Saldanha se enquadra em uma FD que não concorda com as publicações do Charlie Hebdo, as vozes acionadas revelam pertencer a uma FD que assume uma posição a favor da liberdade de expressão.

Saldanha apresenta posicionamento contrário à total liberdade de expressão e, no que tange à regulamentação da mídia brasileira, pode-se pensar, inclusive, que ela seja favorável, uma vez que seu discurso está permeado por uma FD em confronto com o que a Veja defende, já que se pode inferir que o periódico considera a regulamentação da mídia como forma de censura pela esquerda política como é possível perceber nos trechos abaixo, retirados de matérias publicadas pela Veja:

O PT quer, sim, a censura — chama a isso de "controle social" —, mas a represidenta diz se contentar com a 'regulação econômica'. O que é isso? Ela não diz. Não dizendo, tanto melhor! Ganha a simpatia de grupos que têm a esperança de entrar no setor e espera contar com a mansidão daqueles que podem vir a ser prejudicados. Em certo sentido, a melhor coisa que o PT pode fazer para 'controlar a mídia' é manter a permanente ameaça de... controle da mídia, entenderam? [...]

Em um vídeo postado pelo PT no Facebook da presidente, Dilma defende regulação econômica da mídia, novo apelido para censura. Ela volta a falar sobre monopólios e oligopólios num país com milhares de emissoras de rádio e TV. O plano é enfraquecer a imprensa livre.

Vale ressaltar, todavia, que o posicionamento político entre as vozes acionadas na SD 4 e Saldanha é o mesmo - todos estão inscritos em uma FD que tende à esquerda política, fato silenciado pelo colunista, razão pela qual os dizeres dos personagens foram justificados (para Saldanha, Ziraldo e o DCM fizeram tais afirmações por conta da emoção momentânea gerada pela morte dos cartunistas) em vez de serem simplesmente condenados pelo autor.

$\mathrm{O}$ autor justificou as falas como sendo resultado de um momento de emoção, da suavização gerada pela morte dos cartunistas. Essa colocação parte da ideia socialmente aceita de que a morte ameniza ou até justifica os erros cometidos em vida. Aqui, evoca-se a memória discursiva, que, segundo Pêcheux (1999, p. 52), "seria aquilo que [...] vem restabelecer os ‘implícitos' (quer dizer, mais tecnicamente, os pré-construídos, elementos citados e relatados, discursos transversos, etc.) de que sua leitura necessita: a condição do legível em relação ao 
próprio legível". Ou seja, faz parte do entendimento social coletivo que se deve respeitar a pessoa após sua morte e não lembrar seus feitos negativos: no caso, deve-se respeitar os cartunistas que morreram.

Todavia, o colunista não assume para si essa posição, pois, para ele, o assassinato dos cartunistas não abrandou a intenção deles de provocar e ofender a religião islâmica por meio das caricaturas. Saldanha busca deixar claro que os cartunistas estavam cientes da possível repercussão de seus atos.

O colunista ainda coloca que as charges de Charlie Hebdo são de péssimo gosto, mas que isso não está em questão. Contudo, se não estivesse de fato em questão, não seria mencionado por Saldanha; mas, ao mencionar, o autor faz uma tentativa de controlar o sentido construído, pois deixa 'no ar' a ideia de que realmente são de péssimo gosto as publicações, esperando que o leitor assuma para si essa opinião. Além disso, o foco do colunista é a crítica à intolerância, sendo secundária a crítica à qualidade das publicações.

Vale ressaltar que Charlie Hebdo, antes do atentado, possuía uma tiragem semanal de 60 mil cópias, ou seja, é possível inferir que, para o público consumidor da revista, talvez as publicações não fossem de péssimo gosto, pois, se assim considerasse, possivelmente este público não compraria a revista.

\section{CONSIDERAÇÕES FINAIS}

Pela análise do corpus desta pesquisa, foram observadas as diferenças ideológicas dos periódicos Veja e Carta Maior materializadas nos discursos disseminados pelas publicações, uma vez que dizer é mobilizar FDs. Com isso, identificou-se a inserção da Veja e do colunista Ricardo Setti em uma FD que se posiciona favoravelmente à liberdade de expressão, que mobiliza uma FD de direita e uma FD neoliberal, enquanto a Carta Maior e o jornalista Rafo Saldanha se inserem em uma FD que demonstra contrariedade no que tange à total liberdade de expressão, mobilizando uma FD de esquerda e, em alguns momentos, uma FD cristã, todas elas atravessadas pelo interdiscurso.

Diante disso, cada um dos veículos de comunicação apontou causas distintas para o atentado contra o periódico Charlie Hebdo, ocorrido em janeiro de 2015. Assim, o objetivo das análises realizadas era de elucidar, considerando que a linguagem não é transparente nem inocente, alguns dos efeitos de sentido construídos a partir das SDs selecionadas, que revelam as posições assumidas pela Veja e pela Carta Maior, já que, 
[...] do ponto de vista da análise do discurso, o que importa é destacar o modo de funcionamento da linguagem, sem esquecer que esse funcionamento não é integralmente linguístico, uma vez que dele fazem parte as condições de produção, que representam o mecanismo de situar os protagonistas e o objeto do discurso (ORLANDI, 2011, p. 117).

Nesse ínterim, uma das perguntas que embasavam esta pesquisa- por que Veja e Carta Maior dizem o que dizem da forma como dizem? - foi respondida observando-se que as FDs em que Veja e Carta Maior se inserem, apesar de convergirem em relação a alguns temas, como a valorização e o respeito à vida humana, já que é um valor presente no interdiscurso, estão em constante embate no campo discursivo. Enquanto a FD assumida pela Carta Maior criticou a justiça francesa por não ter censurado as publicações do Charlie Hebdo, a FD que permeia o discurso da Veja defende a não interferência do Estado na liberdade de imprensa, isto é, é a favor da total liberdade de expressão. Dessa forma, para a Veja, a culpa do atentado é da imigração indiscriminada, bem como do fanatismo dos muçulmanos. Já para a Carta Maior, o atentado poderia ter sido impedido, se o governo francês limitasse as publicações do periódico Charlie Hebdo, já que, para a FD que permeia o periódico, a censura, por vezes, é benéfica.

Tanto a Veja quanto a Carta Maior construíram seus discursos buscando gerar o sentido de que falavam a verdade. Contudo, conforme colocado por Mariani (1998) e Gregolin (2007), o discurso jornalístico não retrata o real, já que não é neutro nem imparcial, mas sim constrói a realidade, a partir da ideologia e das FDs que permeiam as empresas jornalísticas. Assim, Ricardo Setti e Rafo Saldanha, assumindo a posição de sujeitos jornalistas, acreditavam controlar o sentido do dizer, bem como de serem a fonte do dizer.

Pelas SDs analisadas, foi percebida a tentativa de controle de sentidos por parte dos colunistas. No discurso disseminado pela Veja, isso ocorreu por meio do silenciamento de dizeres, como as consequências sociais das charges, os princípios da religião islâmica, a lei francesa de liberdade de imprensa e o direito dos imigrantes. Ao mesmo tempo em que Veja silencia determinados dizeres, ela também diz sem usar palavras, isto é, leva a efeitos de sentido que são construídos sem que assuma a responsabilidade por eles. O que não é dito de forma explícita é tão importante quanto o que é, visto que "o não-afirmado precede e domina o afirmado" (PÊCHEUX; FUCHS, 1993, p. 178). Infere-se que o silenciamento ocorre tanto para não assumir aquilo que não se ousa dizer com palavras quanto na tentativa de não gerar sentidos outros não desejados. Além disso, o dito e o não dito funcionam por causa da própria FD, que delimita o que pode e deve ser enunciado.

A Carta Maior, ao tentar controlar os sentidos, busca amenizar a culpa dos criminosos para colocar o foco na culpa do governo francês. Trata-se de controlar os sentidos não para que se exima os terroristas de sua culpa, mas para que eles sejam vistos como vítima da intolerância 
religiosa, já que o atentado não teria acontecido, se o periódico Charlie Hebdo respeitasse a crença do outro. O controle de sentidos se deu também por meio do uso das aspas, marcas da heterogeneidade mostrada, em que o sujeito busca se eximir da responsabilidade daquilo que disse.

A Veja mostra-se contrária à legalização da imigração e defende a meritocracia sem que o país ofereça oportunidades de ascensão profissional para os estrangeiros. Para essa FD, a imigração ilegal sim é benéfica, pois, além de serem mão de obra barata, os imigrantes não recebem dinheiro público, o que contribui com a economia do país. Ressalta-se, todavia, que a Veja não vê como inferior tudo o que é estrangeiro, já que valoriza aquilo que é hegemônico. Por meio de paráfrases, Veja (re)afirma os sentidos efetivados, enunciando de diferentes formas aquilo que já havia sido dito.

A questão da imigração não foi mencionada pela Carta Maior. Com isso, infere-se que para ela o problema está na intolerância dos cartunistas franceses, não nos imigrantes. Além disso, por vezes, a Carta Maior mobilizou a FD cristã em seu discurso, pois "uma FD não é um espaço estrutural fechado, pois é constitutivamente 'invadida' por elementos que vêm de outro lugar (isto é, de outras FD) que se repetem nela, fornecendo-lhe suas evidências discursivas fundamentais [...]" (PÊCHEUX, 1997, p. 314). Um exemplo é a afirmação de que a morte é a sentença final, que não permite evolução. A evolução a que a FD se refere é o arrependimento, e a morte não possibilitaria que isso acontecesse.

Observa-se a alteração de sentido nas FDs para um dos preceitos da crença islâmica: para a FD que permeia o discurso da Carta Maior, não representar a imagem dos profetas é um princípio que deve ser seguido e respeitado pela população, mas, para a FD que atravessa o discurso da Veja, isso é visto como fanatismo. As expressões "liberdade de imprensa" e "liberdade de expressão" também adquirem sentidos distintos nas FDs, já que a Veja as enxerga como sinônimos, e a Carta Maior as diferencia.

A construção de sentidos ocorre de acordo com a FD; por isso, um mesmo enunciado/acontecimento é avaliado e interpretado de formas distintas, e isso foi o que se buscou mostrar com este trabalho, uma vez que o ataque contra o periódico Charlie Hebdo gerou incontáveis construções de sentido.

$\mathrm{O}$ ataque estava relacionado a três temas que, conforme já mencionado, são considerados pela sociedade como polêmicos: religião, imigração e liberdade de imprensa. Por isso, a análise da repercussão midiática do atentado, que não deixa de estar vinculada a ideais políticos, torna-se delicada por ser algo que ultrapassa o próprio acontecimento, já que os sentidos dos enunciados nunca estão prontos e acabados, pois linguagem, história e ideologia estão articuladas nos discursos dos sujeitos. 


\section{NOTAS}

1 Evento organizado por movimentos sociais de muitos continentes cujo objetivo é elaborar alternativas para uma transformação social global.

2 Eu não sou Charlie.

3 Eu sou Charlie.

${ }^{4}$ O termo cristã foi utilizado para nomear a FD em questão pela dificuldade de encontrar um termo mais específico, já que os posicionamentos adotados pela FD citada não são, necessariamente, adotados por todas as religiões cristãs.

\section{REFERÊNCIAS}

BAKHTIN, M. Marxismo e filosofia da linguagem. 9. ed. São Paulo: Hucitec, 1999.

GREGOLIN, M. R. V. Discurso e Memória: Movimentos na Bruma da Historia. In: Cadernos da Faculdade de Filosofia e Ciências. Marília: UNESP, 1997, p. 45-58.

2007.

. Foucault e Pêcheux na análise do discurso: diálogos e duelos. São Carlos: Claraluz,

INDURSKY, F. Formação discursiva: ela ainda merece que lutemos por ela? In: SEMINÁRIO DE ESTUDOS EM ANÁLISE DO DISCURSO - SEAD, 2, 2005. Porto Alegre. Anais. Porto Alegre:UFRGS, 2005.

MARIANI, Bethania. O PCB e a imprensa: os comunistas no imaginário dos jornais (1922-1989). Rio de Janeiro: Revan; Campinas, SP: Editora da Unicamp, 1998.

NARLOCH, L. A LIVRE IMIGRAÇÃO É UMA BANDEIRA DA ESQUERDA OU DA DIREITA? Disponível em: <http://veja.abril.com.br/blog/cacador-de-mitos/imigracao/a-livreimigracao-e-uma-bandeira-da-esquerda-ou-da-direita/>. Acesso em: 22 de nov. de 2015.

NAVARRO, Pedro. O pesquisador da mídia: entre a "aventura do discurso" e os desafios do dispositivo de interpretação da AD. In: NAVARRO, Pedro. (Org). Estudos do Texto e do Discurso. São Carlos: Claraluz, 2006.

ORLANDI, E. Análise do discurso: princípios e procedimentos. Campinas: Pontes, 2007/2010. 2011.

. A linguagem e seu funcionamento: as formas do discurso. 6. ed. Campinas: Pontes,

ORSATTO, Franciele Luzia de Oliveira. Outra mesma imagem de mulher: a representação do feminino na revista Nova. 2014. 194 p. Tese (Doutorado em Letras) - Universidade Estadual do Oeste do Paraná.

PÊCHEUX, M.; FUCHS, C. A propósito da Análise Automática do Discurso:atualização e perspectivas. In: GADET, F. HAK, T. (Orgs.). Por uma análise automática do discurso. Trad. De Bethania Mariani et al. 2. ed. Campinas: Editora da Unicamp, 1993. 
PÊCHEUX, M. A forma-sujeito do discurso. In: PÊCHEUX, M. Semântica e discurso: uma crítica à afirmação do óbvio. Trad. de E.P. Orlandi et. Al. Campinas, SP: Unicamp, 2009, p. $145-168$.

. A análise de discurso: três épocas (1983). In: GADET, F. HAK, T. (Orgs). Por uma análise automática do discurso: uma introdução à obra de Michel Pêcheux. Campinas: Editora da Unicamp, 2010.

. Língua, "linguagens", discurso. In: PÊCHEUX, M. Análise de discurso: Michel Pêcheux. (Textos selecionados por Eni Orlandi). 3. ed. Campinas: Ponte Editores, 2011.

. Papel da memória. In: ACHARD, P. et al. Papel da memória. Tradução e introdução de José Horta Nunes. Campinas: Pontes, 1999, p. $49-57$.

ZANELLA, Alexandre da Silva. Metrópoles do futuro: o barulho por trás do ranking da Veja. 2012. 118 p. Dissertaçãoo (Mestrado em Letras) - Programa de Pós-Graduação em Letras, Universidade Estadual do Oeste do Paraná - UNIOESTE, 